\title{
Life Distribution Transformation Model of Planetary Gear System
}

\author{
Ming Li, Li-Yang Xie* , Hai-Yang Li and Jun-Gang Ren
}

\begin{abstract}
Planetary gear systems have been widely used in transportation, construction, metallurgy, petroleum, aviation and other industrial fields. Under the same condition of power transmission, they have a more compact structure than ordinary gear train. However, some critical parts, such as sun gear, planet gear and ring gear often suffer from fatigue and wear under the conditions of high speed and heavy load. For reliability research, in order to predict the fatigue probability life of planetary gear system, detailed kinematic and mechanical analysis for a planetary gear system is firstly completed. Meanwhile, a gear bending fatigue test is carried out at a stress level to obtain the strength information of specific gears. Then, a life distribution transformation model is established according to the order statistics theory. Transformation process is that, the life distribution of test gear is transformed to that of single tooth, and then the life distribution of single tooth can be effectively transformed to that of the planetary gear system. In addition, the effectiveness of the transformation model is finally verified by a processing method with random censoring data.
\end{abstract}

Keywords: Planetary gear system, Reliability modeling, Probabilistic life, Random censoring data

\section{Introduction}

Planetary gear system has the advantages of light weight, small size, large transmission ratio, powerful bearing capacity and high transmission efficiency [1-3]. Therefore, it has been widely used in a variety of mechanical equipment. Actual situation and experience data have showed that the reliability of key gears (such as sun gear, planet gear and ring gear) has a significant impact on the reliability of the whole transmission system [4]. Therefore, some scholars have predicted the life or reliability of the gear system consisting of these gears. On the basis of considering time-varying meshing stiffness of gears, Qin et al. [5] studied the dynamic reliability of wind turbine gear system. Hu et al. [6] established a reliability model for closed planetary gear system, which considered the effects of load, tooth width and load sharing on reliability of the gear system. Zhou et al. [7] considered reliabilitybased sensitive factors to conduct the reliability analysis for the planetary gear system in shearer mechanism. Li et al. [8] studied the influence of unequal load sharing

*Correspondence: lyxie@mail.neu.edu.cn

Key Laboratory of Vibration and Control of Aviation Propulsion System,

Ministry of Education, Northeastern University, Shenyang 110819, China on the reliability of planetary gear system. Wu et al. [9] established a typical two stage planetary gear transmission reliability model based on the product rule of system reliability. Huang et al. [10] presented a novel method to evaluate the reliability of the kinematic accuracy of gear mechanisms with truncated random variables. Nejad et al. [11] presented a long-term fatigue damage reliability analysis method for tooth root bending in wind turbine drive trains. Shang et al. [12] combined fuzzy mathematics with reliability theory, and adopted multiobjective optimization design to study the design technology of high reliability and high power density for planetary gear transmission in large energy installations. Meanwhile, Hao [13] carried out a multi-objective fuzzy reliability optimization design for the multistage planetary gear system. Zhang et al. [14] applied an improved genetic algorithm to the reliability optimization design of NGW planetary gear transmission to improve the stability and transmission efficiency of the transmission system. In addition, many other researchers have conducted relevant studies [15-18].

In planetary gear system, movement state of each gear is very complicated, and their working environment is generally worse [19]. Therefore, for the validity and
Springer Open

(c) The Author(s) 2018. This article is distributed under the terms of the Creative Commons Attribution 4.0 International License (http://creativecommons.org/licenses/by/4.0/), which permits unrestricted use, distribution, and reproduction in any medium, provided you give appropriate credit to the original author(s) and the source, provide a link to the Creative Commons license, and indicate if changes were made. 
Table 1 Computational results of motion relations

\begin{tabular}{|c|c|c|c|}
\hline Parts & Absolute velocity & Relative velocity & Load quantity \\
\hline Sun gear & $\omega_{\mathrm{s}}$ & $\frac{R_{r}}{R_{\mathrm{s}}+R_{\mathrm{r}}} \omega_{\mathrm{S}}$ & $\frac{R_{r} \omega_{5} n_{p} t}{R_{s}+R_{r}}$ \\
\hline Planet gear & $\frac{R_{\mathrm{s}}}{R_{\mathrm{s}}-R_{\mathrm{r}}} \omega_{\mathrm{S}}$ & $\frac{2 R_{\mathrm{s}} R_{\mathrm{r}}}{R_{\mathrm{S}}^{2}-R_{\mathrm{r}}^{2}} \omega_{\mathrm{S}}$ & $\frac{4 R_{\mathrm{s}} R_{\mathrm{r}} \omega_{\mathrm{s}} n_{\mathrm{p}} t}{R_{\mathrm{r}}^{2}-R_{\mathrm{s}}^{2}}$ \\
\hline Ring gear & 0 & $-\frac{R_{\mathrm{s}}}{R_{\mathrm{s}}+R_{\mathrm{r}}} \omega_{\mathrm{s}}$ & $\frac{R_{s} \omega_{s} n_{p} t}{R_{s}+R_{r}}$ \\
\hline Planet carrier & $\frac{R_{\mathrm{s}}}{R_{\mathrm{s}}+R_{\mathrm{r}}} \omega_{\mathrm{S}}$ & 0 & - \\
\hline
\end{tabular}

simplicity of forecasting method, how to establish model, and how to get input variable for the model should be a focus. A large number of scholars have established the reliability model of planetary gear system based on dynamics theory, which makes the form of the models too complex or difficult to ensure the accuracy. Field or accelerated gear system tests can effectively obtain the life or reliability information, but for planetary gear system, long time and high cost make it difficult to realize [20]. In order to predict the probability life of planetary gear system simply and effectively, this paper combines a simple gear pair meshing test with a life distribution transformation model. Specifically, test result of the special gears (whose parameters are the same as those of service gears) is used as input variables for the transformation model in order to fully reflect the influence of service gear performance on the gear system life. The gear pair meshing test can effectively simulate the running state of gears in planetary gear system to a certain extent, so that the test data will contain a large number of the gear system life information. Therefore, prediction accuracy of the model is guaranteed while its complexity is reduced.

\section{Kinematic and Mechanical Analysis}

\subsection{Kinematic Analysis}

In the same time $t$, the operating speed of each gear in the planetary gear system is different. In order to relate their motion relationships, kinematics analysis of the planetary gear train is required. On the basis of previous research [21], the motion law of planetary gear drive system is as follows

$$
\left\{\begin{array}{l}
\omega_{\mathrm{s}}+\frac{R_{\mathrm{r}}}{R_{\mathrm{s}}} \omega_{\mathrm{r}}-\left(1+\frac{R_{\mathrm{r}}}{R_{\mathrm{s}}}\right) \omega_{\mathrm{c}}=0, \\
\omega_{\mathrm{p}}-\frac{R_{\mathrm{s}}+R_{\mathrm{r}}}{R_{\mathrm{s}}-R_{\mathrm{r}}} \omega_{\mathrm{c}}+\frac{2 R_{\mathrm{r}}}{R_{\mathrm{s}}-R_{\mathrm{r}}} \omega_{\mathrm{r}}=0,
\end{array}\right.
$$

where $\omega_{\mathrm{s}}, \omega_{\mathrm{p}}, \omega_{\mathrm{r}}, \omega_{\mathrm{c}}$ are respectively the absolute angular velocity of sun gear, planet gear, ring gear and planet carrier and, $R_{\mathrm{S}}$ and $R_{\mathrm{r}}$ are the radii of pitch circle of sun gear and ring gear respectively. The absolute angular velocity of each gear, angular velocity relative to planet carrier, and the number of loads on a gear (if the gear is loaded once, this means that each tooth of the gear is loaded once) in time $t$ can be known by Eq. (1). And they are listed in Table 1, in which, minus sign shows opposite rotation direction, and $n_{\mathrm{p}}$ is the number of planet gears in the system.

\subsection{Calculation of Root Bending Stress}

Bending fatigue failure of tooth root is the most common and dangerous failure form for gears, so this paper takes it as the failure mode of reliability analysis. When calculating the root bending stress, the tooth can be regarded as a cantilever beam, and its dangerous section is determined by the $30^{\circ}$ tangent method. As shown in Figure 1, $h_{\mathrm{F}}$ is the length of arm, $S_{\mathrm{F}}$ is the thickness of dangerous section, $\rho_{\mathrm{r}}$ is the fillet radius at root, $\alpha_{\mathrm{a}}$ is the direction of normal force at addendum. The angle between $A B$ and the symmetrical center line of tooth is 30 , and $A B$ is tangent to the fillet radius at root, and $A C$ is the same as $A B$. The cross section that connects the two tangent points $B$ and $C$, and is parallel to the axis of gear is just the dangerous section, which is the main location of the bending fatigue crack of teeth.

In the condition of a pair of teeth are meshed, the maximum bending stress on the dangerous section is calculated based on the full load acting on the top of tooth. The normal force acting on the top of tooth is

$$
F_{\mathrm{n}}=\frac{2 T_{1}}{d_{1} \cos \alpha},
$$

where $T_{1}$ is the torque of driving gear, and $d_{1}$ is its pitch diameter, and $\alpha$ is the pressure angle.

If the friction between teeth is neglected, the normal force acting on the top of tooth can be divided into two forces $F_{\mathrm{n}} \cos \alpha_{\mathrm{a}}$ and $F_{\mathrm{n}} \sin \alpha_{\mathrm{a}}$, as shown in Figure 2.

Since the shear stress produced by $F_{\mathrm{n}} \cos \alpha_{\mathrm{a}}$ and the compressive stress produced by $F_{\mathrm{n}} \sin \alpha_{\mathrm{a}}$ are much smaller than the bending stress produced by $F_{\mathrm{n}} \cos \alpha_{\mathrm{a}}$,

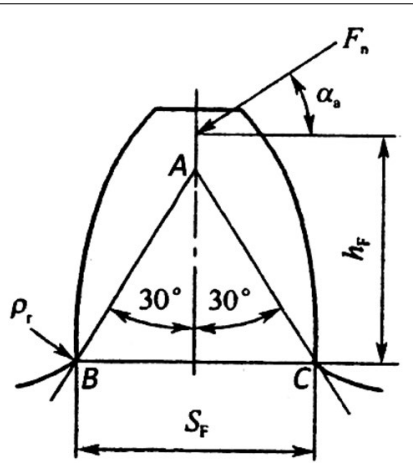

Figure 1 Dangerous section of tooth bending fatigue 
thus the minimum values can be ignored. Then, the root bending stress is

$$
\sigma_{\mathrm{F}}=\frac{F_{\mathrm{n}} h_{\mathrm{F}} \cos \alpha_{\mathrm{a}}}{b S_{\mathrm{F}}^{2} / 6},
$$

where $b$ is tooth width.

Equation (2) is substituted into Eq. (3)

$$
\sigma_{\mathrm{F}}=\frac{2 K T_{1}}{b d_{1} m} \frac{6\left(\frac{h_{\mathrm{F}}}{m}\right) \cos \alpha_{\mathrm{a}}}{\left(\frac{S_{\mathrm{F}}}{m}\right)^{2} \cos \alpha},
$$

where $K$ is load factor. And make

$$
Y_{\mathrm{F}}=\frac{6\left(\frac{h_{\mathrm{F}}}{m}\right) \cos \alpha_{\mathrm{a}}}{\left(\frac{S_{\mathrm{F}}}{m}\right)^{2} \cos \alpha},
$$

at the same time, a stress correction coefficient $Y_{\mathrm{S}}$ and a coincidence degree coefficient $Y_{\varepsilon}$ are introduced, and finally the root bending stress is expressed commonly

$$
\sigma_{\mathrm{F}}=\frac{2 K T_{1}}{b d_{1} m} Y_{\mathrm{F}} Y_{\mathrm{S}} Y_{\varepsilon}
$$

where $Y_{\mathrm{F}}$ is tooth shape coefficient, which is related to the shape of tooth profile, regardless of the modulus. $Y_{\mathrm{S}}$ is stress correction coefficient, which can take into account the stress concentration at tooth root. And $Y_{\varepsilon}$ is contact ratio coefficient.

The root bending stress calculated by Eq. (5) is a maximum tensile stress on the dangerous section at the load side of tooth (the root bending stress mentioned in this paper all refers to this maximum stress), as shown in Figure 2. It calculates the peak value of bending stress at tooth root during meshing process, so a load history of the tooth can be given in a series of discrete values. At

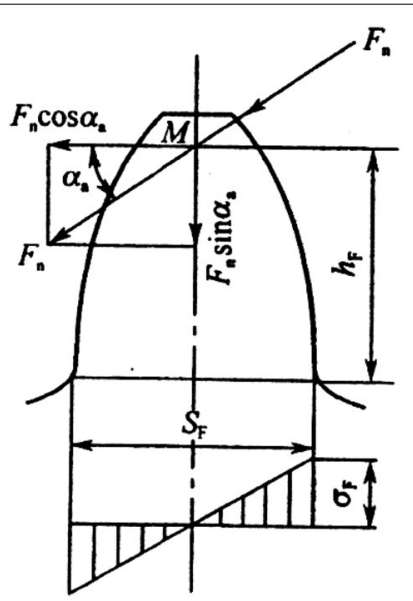

Figure 2 Root bending stress calculation the same time, RomaxDesigner software is used to calculate the stress, which is based on Eq. (5) and can accurately reflect the effect of centrifugal force on stress. The simulation model of a NGW planetary gear system is shown in Figure 3 and, the number of planet gears in the system is $n_{\mathrm{p}}=3$, rated input speed of the system is $2000 \mathrm{r} /$ $\mathrm{min}$, and rated input power is $10 \mathrm{~kW}$. System parameters and stress calculation results are presented in Table 2.

\section{Gear Fatigue Test}

Bending fatigue fracture of teeth is the most severe failure type for gears $[22,23]$, which may lead to a direct collapse of the power transmission system. More seriously, in the field of aviation, fracture of the teeth can lead to serious accidents [24]. Therefore, a gear bending fatigue test is carried out to collect the life data of specific gears and to use the statistical result as input variable for the transformation model.

\subsection{Gear Sample}

The gear samples are standard cylindrical helical gears designed according to the parameters of gear in the planetary gear system. The sample parameters and appearance are shown in Table 3 and Figure 4, respectively.

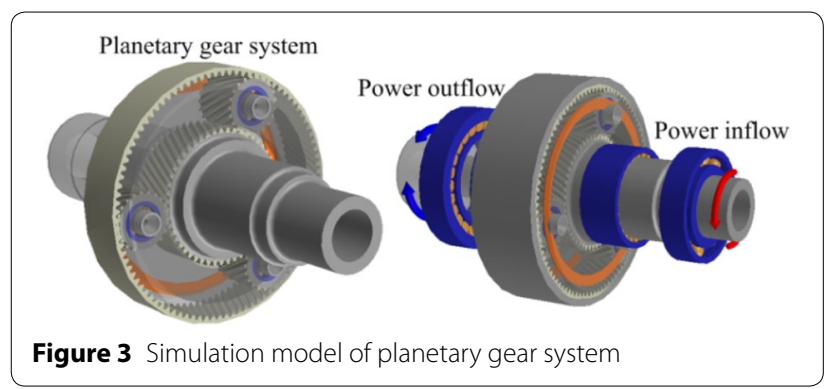

Table 2 System parameters and stress calculation results

\begin{tabular}{llll}
\hline Parameters & Sun gear & Planet gear & Ring gear \\
\hline Normal modulus $(\mathrm{mm})$ & 1 & 1 & 1 \\
Number of teeth & 51 & 21 & 93 \\
Pressure angle $\left({ }^{\circ}\right)$ & 20 & 20 & 20 \\
Helix angle $\left(^{\circ}\right)$ & 26 & 26 & 26 \\
Face width $(\mathrm{mm})$ & 22 & 21.5 & 22 \\
Tooth thickness $(\mathrm{mm})$ & 1.49 & 1.55 & 1.57 \\
Profile shift coefficient & -0.1 & 0 & 0 \\
Root fillet radius $(\mathrm{mm})$ & 0.41 & 0.42 & 0.15 \\
Root roughness $(\mu \mathrm{m})$ & $R_{\mathrm{z}}=10$ & $R_{\mathrm{z}}=10$ & $R_{\mathrm{z}}=10$ \\
ISO quality grade & 6 & 6 & 6 \\
Material & $20 \mathrm{CrMnTi}$ & $20 \mathrm{CrMnTi}$ & $20 \mathrm{CrMnTi}$ \\
Root stress $(\mathrm{MPa})$ & 388 & 362 & 420 \\
\hline
\end{tabular}


Table 3 Parameters of gear sample

\begin{tabular}{llll}
\hline Parameters & Values & Parameters & Values \\
\hline Normal modulus $(\mathrm{mm})$ & 3.7 & Root radius $(\mathrm{mm})$ & 2 \\
Number of teeth & 27 & Root roughness $(\mu \mathrm{m})$ & $R_{\mathrm{z}}=10$ \\
Pressure angle $\left(^{\circ}\right)$ & 20 & ISO quality grade & 6 \\
Helix angle $\left(^{\circ}\right)$ & 26 & Material & 20CrMnTi \\
Face width $(\mathrm{mm})$ & 20 & Case depth $(\mathrm{mm})$ & $0.8 \pm 0.13$ \\
Tooth thickness $(\mathrm{mm})$ & 6.6 & Surface hardness & HRC59-63 \\
Base pitch $(\mathrm{mm})$ & 11.8 & Core hardness & HRC35-48 \\
Modification coefficient & 0.1 & Precision machining & Grinding \\
\hline
\end{tabular}

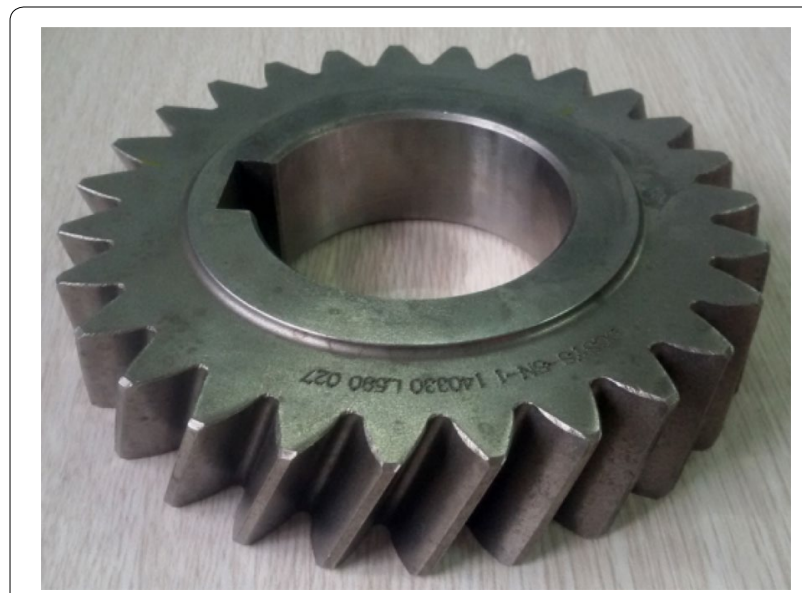

Figure 4 Gear sample

The manufacturing process begins with rough forging, followed by roughing, high temperature normalizing, semi-finishing, hobbing, shaving, carburizing and final grinding. Specifically, carburizing temperature is $920-930{ }^{\circ} \mathrm{C}$, oil quenching temperature is $820{ }^{\circ} \mathrm{C}$ and tempering temperature is $180{ }^{\circ} \mathrm{C}$. All the gears are made of the same equipment and process.

\subsection{Experimental Equipment}

The main body of experimental equipment is a power flow closed gear rotating tester, as shown in Figure 5. Load is added by the mechanical levers and weights, and motor speed remains constant at $3460 \mathrm{r} / \mathrm{min}$. Center distance of gear pair on the tester is $100 \mathrm{~mm}$, and transmission ratio is 1:1. A vibration monitoring instrument is used to achieve automatic shutdown when any tooth fracture occurs. Oil injection position and flow can be adjusted to ensure good lubrication. Circulating water system keeps the return oil temperature below $60^{\circ} \mathrm{C}$. The error of circulation recording device is not more than $\pm 0.1 \%$. Before starting experiment, the equipment is calibrated based on the requirements of GB/T 14230 so as to meet the test accuracy.

\subsection{Test Method and Result}

According to the stress calculation of three kinds of gears in Table 2, we need to get the life distributions of gear specimens under the stresses of $420 \mathrm{MPa}, 388 \mathrm{MPa}$, and $362 \mathrm{MPa}$. The life data of ten pairs of gear specimens are obtained under the stress level of $420 \mathrm{MPa}$ and are fitted with Weibull distribution function. Because the life at the other two stress levels is too long, their distributions can be obtained according to the life distribution of $420 \mathrm{MPa}$ and the life probability mapping principle proposed in Ref. [25], the results are shown in Figure 6.
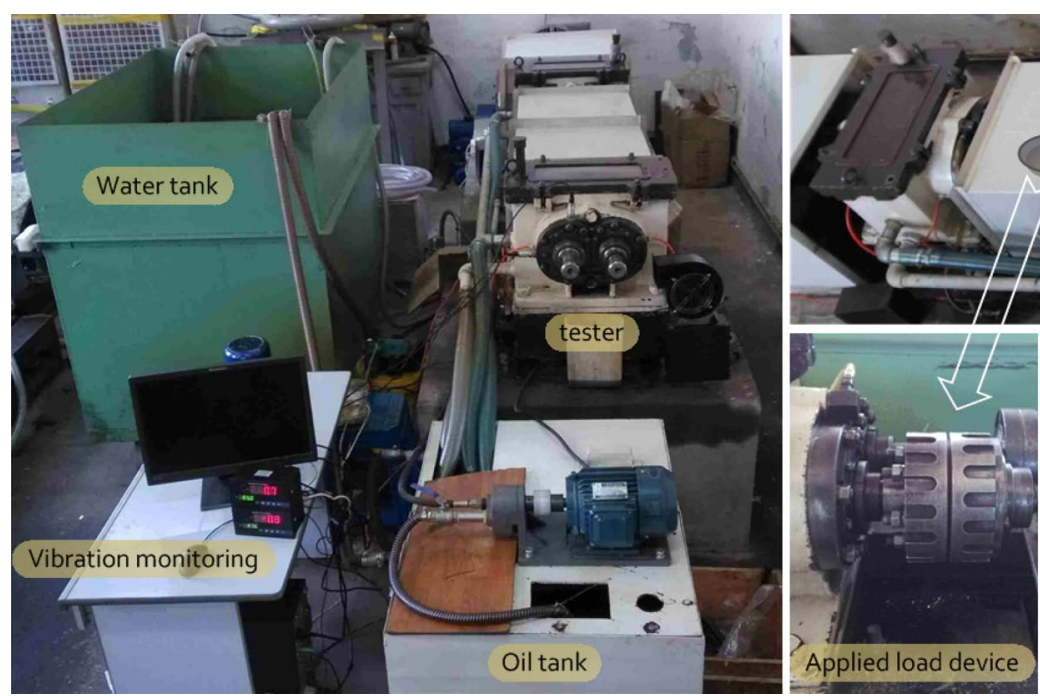

Figure 5 Experimental equipment 


\section{Life Distribution Transformation Model}

The concept of minimum order statistics can be applied to the establishment of transformation model, the concept can be described as, $n$ samples are extracted from a population and then the minimum sample is chosen, repeating this action, the final distribution from these minimum samples is just the minimum order statistics distribution of the population. If the probability density function of $X$ is $f(x)$, and the cumulative distribution function is $F(x)$, the probability density function of the minimal order statistics is given by Eq. (6)

$$
g(x)=z[1-F(x)]^{z-1} f(x) .
$$

For the probabilistic life prediction of gear, we consider a single gear as a sequential system, with each tooth as a component in the system. If any teeth failed, the gear would not be able to fulfill its function of power or motion transmission, thus resulting in failure of the sequential system. According to the definition of order statistics, the gear probabilistic life equals the minimal order statistics of the single tooth probabilistic life [26].

If the number of teeth on a gear is $z$, then by integrating both sides of Eq. (6), we can derive the cumulative distribution function of minimal order statistics $G(n)$, which is just the cumulative distribution function of gear life

$$
G(n)=1-[1-F(n)]^{z},
$$

where $F(n)$ is the cumulative distribution function of the tooth.

By transforming Eq. (7) the cumulative distribution function of the tooth life expressed by gear life can be obtained.

$$
F(n)=1-[1-G(n)]^{1 / z} .
$$

The fatigue life distribution of the gear can be expressed as a two-parameter Weibull distribution [27], and its cumulative distribution function is given by Eq. (9)

$$
G(n)=1-\exp \left[-\left(n / \theta_{0}\right)^{\beta_{0}}\right], n>0,
$$

where $\beta_{0}$ is the geometric parameter of gear life distribution, and $\theta_{0}$ is corresponding scale parameter.

By substituting Eq. (9) into Eq. (8), then Eq. (10) is produced, Eq. (10) has the same meaning as Eq. (8): the probabilistic life of the gear with $z$ teeth is converted into the probabilistic life of single tooth. From the

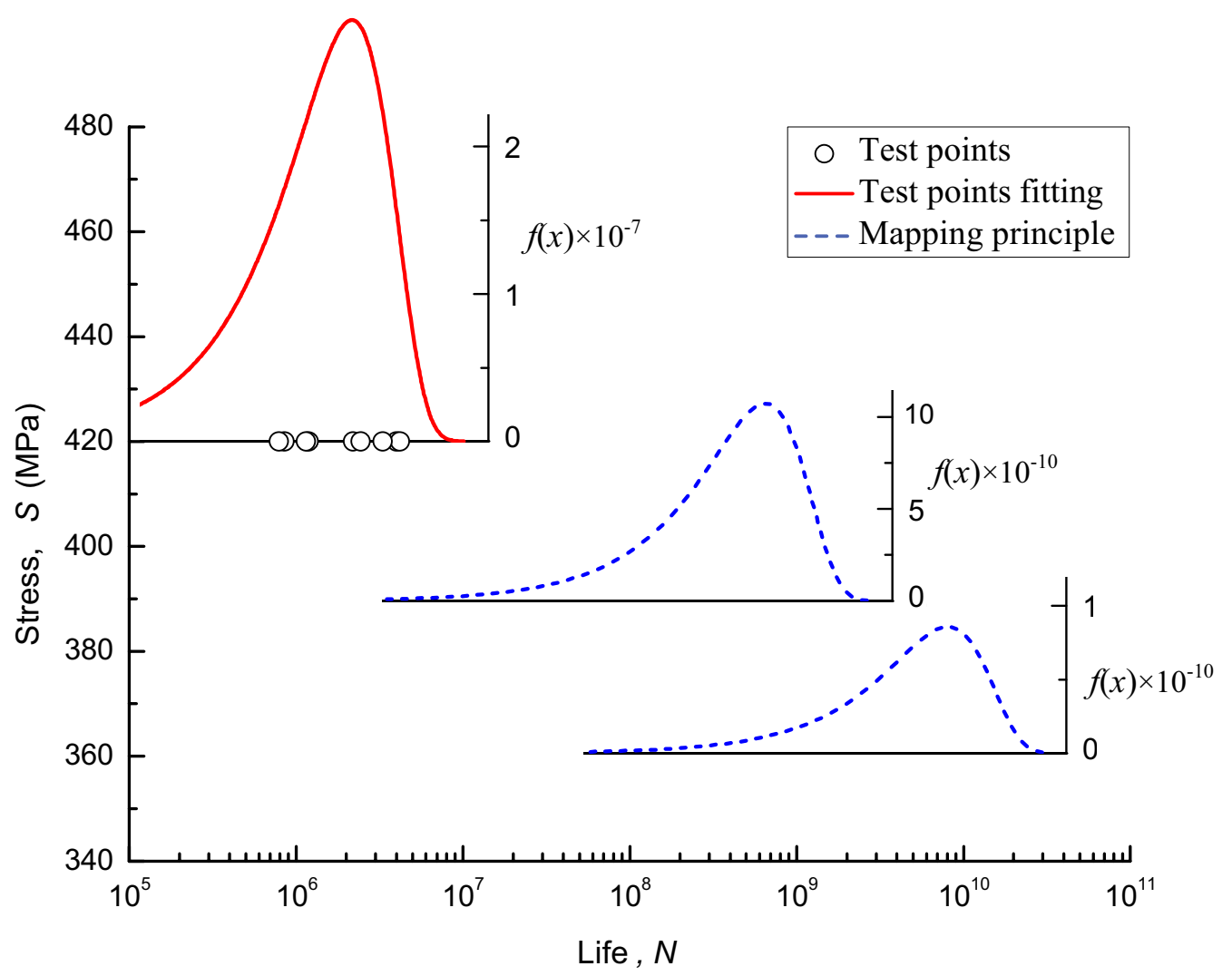

Figure 6 Test data and fitting results 
pattern of the distribution function the life distribution of tooth also conform to the two-parameter Weibull distribution, where the geometric parameter of tooth life distribution is $\beta_{1}=\beta_{0}$, and the scale parameter changes to $\theta_{1}=\theta_{0} z^{1 / \beta_{0}}$.

$$
F(n)=1-\exp \left[-\left(n /\left(\theta_{0} z^{1 / \beta_{0}}\right)\right)^{\beta_{0}}\right], n>0 .
$$

In the planetary gear system, the sun gear, planet gear, and ring gear engage with each other, so they have the same modulus and thus have the same carrying capacity. If material properties of all the gears are also the same, the strength of the teeth can be considered the same. Therefore, the tooth life under a given load level can be considered as the random variable with independent and identical distribution. Furthermore, based on the probabilistic life of tooth and the concept of minimal order statistics, a probabilistic life transformation model of planetary gear system is established.

When the cumulative distribution function of the tooth life $F(n)$ is determined, then the life cumulative distribution functions of sun gear, planet gear, and ring gear can be determined based on Eq. (7)

$$
\left\{\begin{array}{l}
G_{\mathrm{s}}(n)=1-\left[1-F_{\mathrm{s}}(n)\right]^{z_{\mathrm{s}}} \\
G_{\mathrm{p}}(n)=1-\left[1-F_{\mathrm{p}}(n)\right]^{z_{\mathrm{p}}}, \\
G_{\mathrm{r}}(n)=1-\left[1-F_{\mathrm{r}}(n)\right]^{z_{\mathrm{r}}}
\end{array}\right.
$$

where $z$ is the number of teeth, and $\mathrm{s}, \mathrm{p}, \mathrm{r}$ represent different types of gears in planetary gear system and meanwhile express the cumulative distribution functions under different stress levels.

According to reliability product theorem, the cumulative distribution function of the planetary gear system life is given by Eq. (12)

$$
F_{\text {sys }}(n)=1-\left[1-F_{\mathrm{s}}(n)\right]^{z_{\mathrm{S}}}\left[1-F_{\mathrm{p}}(n)\right]^{n_{\mathrm{p}} \cdot z_{\mathrm{p}}}\left[1-F_{\mathrm{r}}(n)\right]^{z_{\mathrm{r}}} .
$$

By substituting the number of load actions in Table 1 into Eq. (12), then the load acting numbers of each gear can be unified into time $t$

$$
\begin{aligned}
F_{\text {sys }}(t)=1- & {\left[1-F_{\mathrm{s}}\left(\frac{R_{\mathrm{r}} \omega_{\mathrm{s}} n_{\mathrm{p}} t}{R_{\mathrm{s}}+R_{\mathrm{r}}}\right)\right]^{z_{\mathrm{s}}} \times } \\
& {\left[1-F_{\mathrm{p}}\left(\frac{4 R_{\mathrm{s}} R_{\mathrm{r}} \omega_{\mathrm{s}} n_{\mathrm{p}} t}{R_{\mathrm{r}}^{2}-R_{\mathrm{s}}^{2}}\right)\right]^{n_{\mathrm{p}} \cdot z_{\mathrm{p}}} \times } \\
& {\left[1-F_{\mathrm{r}}\left(\frac{R_{\mathrm{s}} \omega_{\mathrm{s}} n_{\mathrm{p}} t}{R_{\mathrm{s}}+R_{\mathrm{r}}}\right)\right]^{z_{\mathrm{r}}} . }
\end{aligned}
$$

Weibull distribution function of the tooth life is shown as Eq. (14)

$$
F(t)=1-\exp \left[-\left(t / \theta_{1}\right)^{\beta_{1}}\right], t>0 .
$$

By substituting Eq. (14) into Eq. (13) we get Eq. (15)

$$
\begin{array}{r}
F_{\text {sys }}(t)=1-\exp \left[-z_{\mathrm{s}}\left(\frac{R_{\mathrm{r}} \omega_{\mathrm{s}} n_{\mathrm{p}} t}{\left(R_{\mathrm{s}}+R_{\mathrm{r}}\right) \theta_{1}}\right)^{\beta_{1}}-\right. \\
\left.n_{\mathrm{p}} \cdot z_{\mathrm{p}}\left(\frac{4 R_{\mathrm{s}} R_{\mathrm{r}} \omega_{\mathrm{s}} n_{\mathrm{p}} t}{\left(R_{\mathrm{r}}^{2}-R_{\mathrm{s}}^{2}\right) \theta_{1}}\right)^{\beta_{1}}-z_{\mathrm{r}}\left(\frac{R_{\mathrm{s}} \omega_{\mathrm{s}} n_{\mathrm{p}} t}{\left(R_{\mathrm{s}}+R_{\mathrm{r}}\right) \theta_{1}}\right)^{\beta_{1}}\right] .
\end{array}
$$

\section{Model Validation}

\subsection{Random Censoring Data}

In life-cycle testing some products fail, so an accurate failure time (i.e., product life failure data) can be obtained; while other products may exit the test before failure due to some reasons, thereby obtaining a higher life than the testing time, namely the life censoring data. The failure data and censoring data are generally called random censoring data.

In order to verify the transformation model, the processing method with random censoring data is used. The gear test will stop when any tooth breaks, thereby deriving failure data by the tooth and censoring data of the other teeth. By processing the random censoring data of the teeth, the distribution of tooth life can be obtained, and it can be compared with the results of the transformation model.

\subsection{Estimating Distribution Parameters of Random Censoring Data}

Maximum likelihood estimation possesses obvious advantages in processing censoring data. Due to the large sample size of random censoring data, this method is used to estimate the distribution parameters. Generally the distribution of fatigue life can be represented by a two-parameter Weibull distribution with the distribution function given by Eq. (9), where $\beta$ and $\theta$ are the parameters to be estimated. The random censoring data are represented by $\left(t_{1}, \delta_{1}\right),\left(t_{2}, \delta_{2}\right), \ldots,\left(t_{n}, \delta_{n}\right)$, where $t_{i}$ is observation datum for the $i$ th product. When $\delta_{i}=1, t_{i}$ is the failure data, and when $\delta_{i}=0, t_{i}$ is the censoring data. The likelihood function of $(\beta, \theta)$ is given by Eq. (16) [28]

$$
L(\beta, \theta)=\prod_{i=1}^{n}\left[F^{\prime}\left(t_{i}, \beta, \theta\right)\right]^{\delta_{i}}\left[1-F\left(t_{i}, \beta, \theta\right)\right]^{1-\delta_{i}} .
$$

The maximum likelihood estimation $\beta$ is the root of Eq. (17)

$$
\frac{1}{\beta}+\frac{\sum_{i=1}^{n} \delta_{i} \ln t_{i}}{\sum_{i=1}^{n} \delta_{i}}-\frac{\sum_{i=1}^{n} t_{i}^{\beta} \ln t_{i}}{\sum_{i=1}^{n} t_{i}^{\beta}}=0 .
$$

When $\beta$ is solved, the maximum likelihood estimation $\theta$ can be given by Eq. (18)

$$
\theta=\left(\sum_{i=1}^{n} t_{i}^{\beta} / \sum_{i=1}^{n} \delta_{i}\right)^{1 / \beta} .
$$




\subsection{Parameters Comparison and Model Validation}

The concept of minimal order statistics is used to create the probabilistic life transformation model. First, the probabilistic life of the tooth is obtained based on that of the specific gear. Then, the probabilistic life of the planetary gear system can be obtained based on the probabilistic life of the tooth. Since the two transformations used the same principle, only the first transformation is actually validated. From Eq. (8), we can know the estimate of the distribution parameters of tooth life. From the process of random censoring data, we can also derive the estimate of distribution parameters of tooth life. The results of the two methods can be compared to validate the rationality of the transformation model.

In the gear test, the gear pairs are engaged to transfer power. The drive gear has a higher dynamic torque than the driven gear [29]. It was also found in the test that all the teeth breaking occurred on the drive gears; thus, the life information of the drive gears is used for the validation of the transformation model.

The ten gear life data in Figure 6 can be used. If the number of teeth in a drive gear is $z$, failure of any tooth will cause the test to stop, and the circulating life is recorded. For the gear, the life data are comprised of the failure data for one tooth and censoring data for the $z-1$ teeth. Given $j$ as the number of "circulating life" obtained during the test, then the failure data of the $j$ teeth and censoring data of the $\mathrm{j}(z-1)$ teeth can be obtained.

The statistical result of random censoring data can well reflect population's situation due to the large sample size. And it can be seen from Figure 7 that the overlap ratio of two curves is very high. Therefore, it illustrates the rationality of the life distribution transformation model. And their relative error of life mean is about $7.8 \%$, and that of life standard deviation is about $8.3 \%$. These means the transformation model can be well used to predict the reliability for planetary gear system. In addition, with different sample sizes, the results of two methods are consistent, it can be known that the two methods are not sensitive to variation in sample size, suggesting that the transformation model is effective in dealing with data of small sample size.

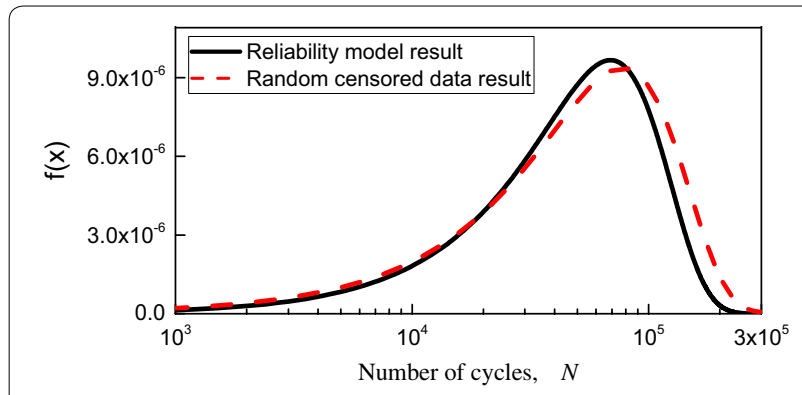

Figure 7 Probability density curves from two methods

\section{Discussion}

(1) The life information of specific gear is taken as the input variables for the transformation model, thereby enabling the model to reflect the large amount of factors that influence system life, which not only improved the prediction precision, but greatly simplified the model as well.

(2) Through the fatigue test, the P-S-N curves of the specific gear can be obtained. Based on the transformation model, the probabilistic life of the planetary gear system at an arbitrary stress level can be derived.

(3) The actual load of the planetary gear system can be first statistically processed, and then the results are applied to the fatigue test with the specific gear, then this method can improve the life prediction precision of the gear system and is more effective for the life prediction of service gear system.

(4) The model does not consider any failure correlation among gears. In practice, the load of gears are random, thus, the results of the transformation model tend to be conservative.

\section{Conclusions}

(1) Based on the concept of minimal order statistics, the model for the probabilistic life transformation for planetary gear system is established. In the model the probabilistic life of single tooth is first calculated based on that of the specific gear. Further, the probabilistic life of the planetary gear system can be estimated based on that of the single tooth.

(2) A gear bending fatigue test is performed at a constant stress level, and the bending fatigue life data of ten $20 \mathrm{CrMnTi}$ carbonized gears are obtained.

(3) The validity of the transformation model is illustrated by the method of random censored data, and it also indicates that the model has the ability to process small sample data. A large number of calculations, analyses and comparisons show that the model is also valid for data with different scatter.

Authors' Contributions

L-YX was in charge of the whole trial; ML wrote the manuscript; $H-Y L$ and J-GR assisted with sampling and laboratory analyses. All authors read and approved the final manuscript.

\section{Authors' Information}

Ming Li, born in 1986, is currently a PhD candidate at School of Mechanical Engineering and Automation, Northeastern University, China. His research interests include mechanical transmission design and fatigue reliability. Tel: +86-13940397486; E-mail: a15941660820@163.com.

Li-Yang Xie, born in 1962, PhD, is currently a professor and a doctorial supervisor at Northeastern University, China. His research interest is reliability theory. Tel: +86-13804011565; E-mail: lyxie@mail.neu.edu.cn.

Hai-Yang Li, born in 1988, is currently a PhD candidate at School of Mechanical Engineering and Automation, Northeastern University, China. His research interests include mechanical transmission design and fatigue reliability. Tel: +86-15940426127; E-mail: naxiaozi_a@126.com. 
Jun-Gang Ren, born in 1982, is currently a PhD candidate at School of Mechanical Engineering and Automation, Northeastern University, China. His research interests include mechanical transmission design and fatigue reliability. Tel: +86-18640345458; E-mail: 289188724@qq.com

\section{Competing Interests}

The authors declare that they no competing interests.

\section{Ethics Approval and Consent to Participate}

Not applicable

\section{Funding}

Supported by National Key Technology Research and Development Program of China (Grant No. 2014BAF08B01), and Natural Science Foundation of China (Grant No. 51335003), and Collaborative Innovation Center of Major Machine Manufacturing in Liaoning Province of China.

\section{Publisher's Note}

Springer Nature remains neutral with regard to jurisdictional claims in published maps and institutional affiliations.

Received: 17 July 2017 Accepted: 9 March 2018

Published online: 10 April 2018

\section{References}

1. S Mo, Y D Zhang, Q Wu, et al. Load sharing behavior of star gearing reducer for geared turbofan engine. Chinese Journal of Mechanical Engineering, 2017, 30(4): 796-803.

2. J Zhang, F Guo. Statistical modification analysis of helical planetary gears based on response surface method and Monte Carlo simulation. Chinese Journal of Mechanical Engineering, 2015, 28(6): 1194-1203.

3. I Miguel. Planetary gear profile modification design based on load sharing modelling. Chinese Journal of Mechanical Engineering, 2015, 28(4): 810-820.

4. M Savage, C A Paridon, J J Coy. Reliability model for planetary gear trains. Transactions of the ASME, Journal of Mechanical, Transmissions, and Automation in Design, 1983, 105: 291-297.

5. D T Qin, Z G Zhou, J Yang, et al. Time-dependent reliability analysis of gear transmission system of wind turbine under stochastic wind load. Journal of Mechanical Engineering, 2012, 48(3): 1-8. (in Chinese)

6. Q C Hu, F H Duan, S S Wu. Research on reliability of closed planetary transmission systems. Chinese Mechanical Engineering, 2007, 18(2): 146149. (in Chinese)

7. D Zhou, X F Zhang, Y M Zhang. Dynamic reliability analysis for planetary gear system in shearer mechanisms. Mechanism and Machine Theory, 2016, 105: 244-259.

8. M Li, LY Xie, L J Ding. Reliability analysis and calculation for planetary mechanism. Chinese Journal of Aeronautics, 2017, 38(8): 1-14. (in Chinese)

9. S S Wu, F H Duan, Q C Hu. The influence of allocation of systematic parameters on the reliability of multi staged planet gear transmission. Journal of Machine Design, 2007, 24(10): 43-45. (in Chinese)

10. X Z Huang, S Hu, Y M Zhang, et al. A method to determine kinematic accuracy reliability of gear mechanisms with truncated random variables. Mechanism and Machine Theory, 2015, 92: 200-212.

11. A R Nejad, Z Gao, T Moan. On long-term fatigue damage and reliability analysis of gears under wind loads in offshore wind turbine drivetrains. International Journal of Fatigue, 2014, 61: 116-128.

12. Z Shang, Z M Liu, C M Wang. Research on design technology of high reliability and high power density for planetary gear transmission. Journal of Machine Design, 2010, 27(6): 48-51. (in Chinese)
13. L P Hao. Fuzzy reliability optimization design with multi-objective for multi-stage planetary gear train. Journal of Mechanical Transmission, 2015 39(1): 87-91. (in Chinese)

14. D H Zhang, F L Wu, ST Zhang, et al. Application of improved genetic algorithm in reliability optimization design of NGW planetary gear transmission. Journal of Mechanical Transmission, 2013, 37(2): 44-46. (in (hinese)

15. G Zhang, G Wang, X Li. Global optimization of reliability design for large ball mill gear transmission based on the kriging model and genetic algorithm. Mechanism and Machine Theory, 2013, 69: 321-336.

16. Y F Li, S Valla, E Zio. Reliability assessment of ge-neric geared wind turbines by GTST-MLD model and Monte Carlo simulation. Renewable Energy, 2015, 83: 222-233.

17. A Guerine, A Elhami, L Walha. A perturbation approach for the dynamic analysis of one stage gear system with uncertain parameters. Mechanism and Machine Theory, 2015, 92:113-126.

18. H J Ren, H Zhang, X G Yu, et al. Nonlinear dynamics of the gear system in five shaft integrally geared centrifugal compressor. Journal of Mechanical Engineering, 2017, 53(9): 1-7 (in Chinese).

19. L Xiang, N Gao, A J Hu. Dynamic analysis of a planetary gear system with multiple nonlinear parameters. Journal of Computational and Applied Mathematics, 2017, 327(2018): 325-340.

20. Z G Zhou, DT Qin, J Yang, et al. Fatigue life prediction of gear transmission system of wind turbine under stochastic wind load. Acta Energiae Solaris Sinica, 2014, 35(7): 1183-1190. (in Chinese)

21. M Li, LY Xie, L J Ding. Load sharing analysis and reliability prediction for planetary gear train of helicopter. Mechanism and Machine Theory, 2017 115: 97-113.

22. DY Zhang, S G Liu. Investigation on bending fatigue failure of a microgear through finite element analysis. Engineering Failure Analysis, 2013, 31 225-235.

23. A Osman. Fatigue failure of a helical gear in a gearbox. Engineering Failure Analysis, 2006, 13: 1116-1125.

24. A S Nauman, K M Deen. Investigating the failure of bevel gears in an aircraft engine. Case Studies in Engineering Failure Analysis, 2013, 1: 24-31.

25. LY Xie. Fatigue reliability evaluation method for gearbox component and system of wind turbine. Journal of Mechanical Engineering, 2014, 50: 1-8. (in Chinese)

26. LY Xie. Issues and commentary on mechanical reliability theories, methods and models. Journal of Mechanical Engineering, 2014, 50(14): 27-35. (in Chinese)

27. ZW An, Y Zhang, B Liu. A method to determine the life distribution function of components for wind turbine gearbox. Journal of University of Electronic Science and Technology of China, 2014, 43(6): 950-954. (in Chinese)

28. M Kateri. On the maximum likelihood estimation of parameters of Weibull distribution based on complete and censored data. Statistics and Probability Letters, 2008, 78: 2971-2975

29. X L Zhu. Gear test technology and equipment. Beijing: China Machine Press, 1988

\section{Submit your manuscript to a SpringerOpen ${ }^{\circ}$ journal and benefit from:}

- Convenient online submission

Rigorous peer review

- Open access: articles freely available online

- High visibility within the field

Retaining the copyright to your article

Submit your next manuscript at springeropen.com 